Original Research Paper

\title{
Application of Water-Soluble Polymers for Extraction Separation of Amino Acids of Various Structures
}

\author{
${ }^{1}$ Nadezhda Yakovlevna Mokshina, ${ }^{2}$ Dmitry Vladimirovich Bykovskiy, \\ ${ }^{2}$ Gennadiy Valentinovich Shatalov and ${ }^{3}$ Oksana Anatolievna Pakhomova \\ ${ }^{1}$ VUNTS Air Force "Air Force Academy Named After Professor Zhukovsky and Yuri Gagarin", \\ Voronezh, 54a Starikh Bolshevikov St., 394063, Russian Federation \\ ${ }^{2}$ Voronezh State University, 1 Universitetskaya Sq., Voronezh, 394006, Russian Federation \\ ${ }^{3}$ Department of Chemistry and Biology, The Institute of Mathematics, \\ Natural Sciences and Technique, Yelets State Bunin University, Russia
}

Article history

Received: 09-10-2015

Revised: 24-10-2015

Accepted: 14-11-2015

Corresponding Author: Nadezhda Yakovlevna

Mokshina

VUNTS Air Force "Air Force

Academy Named After

Professor Zhukovsky and Yuri

Gagarin", Voronezh, 54a

Starikh Bolshevikov St.,

394063, Russian Federation

Email: monblan.pro@yandex.ru

\begin{abstract}
This article actualizes the task of developing new methods for extraction separation of amino acids for the analysis and purification of target components in the production of food supplements, pharmaceuticals, agricultural products and cosmetics; it also presents the extraction separation results for binary mixtures of histidine, proline and methionine using water-soluble homo- and co-polimers with various molecular weight values. We found that with increasing molecular weight of polymers and copolymers, the values of the extraction characteristics are expectedly reduced. The rate of formation of the two-phase system "water-soluble polymer-water-salt solution of amino acid" is largely influenced by the molecular weight of the extractant: As the intrinsic viscosity value $M$ is increased $_{\eta}$ the amount of polymer required for the formation of a heterogeneous system in the presence of a salting-out agent decreases. The influence of the ratio of the aqueous organic phases on the efficiency of the amino acid extraction separation was studied. The degrees of extraction and the separation factors in the methionine-proline and histidine-proline systems were calculated. The amino acids were quantitatively determined using the spectrophotometric method by intrinsic light absorption in the UV region of the spectrum. To improve the efficiency of the amino acids separation, we used the systems additionally containing chloride ions, which promote complexing. Amino acid extraction separation is carried out through the use of environmentally friendly materials, which makes the implementation of the developed methods safe. Two-phase aqueous systems based on water-soluble polymers most fully satisfy the requirements for extraction systems.
\end{abstract}

Keywords: Amino Acids, Extraction, Separation, Spectrophotometry, Water-Soluble Polymers of the Vinyl Sequence

\section{Introduction}

In the circumstances of the modern industry of food supplements, medicines, fodders and vitamin mixtures, the production of amino acids is the most large-scale industry. The main method of obtaining the structural components of proteins and peptides is the fermentation synthesis. Herewith, the number of amino acids of various structures produced by chemical methods increases every year. Histidine, methionine and proline demonstrate the largest volume of production. These amino acids are considered indispensable; their synthesis is an actual problem of biotechnology. Amino acid deficiency contributes to the development of dysfunction of metabolic processes in the human body, so the lack of histidine, methionine and proline must be filled through the additional inclusion of exogenous amino acids in the diet (Berezov and Korovkin, 2004).

Every year, the list of dosage forms containing amino acids in free and bound form is extended (Ivashov, 2013). The directed effect of drugs based on mixtures of amino acids is based on the anabolic and anti-oxidant 
effect, stimulation of energy supply and regeneration. Intake of free-form amino acids is not accompanied by increased energy costs for the splitting at suction, unlike protein (Vorokhobina and Kuznetsov, 2010).

Amino acids are widely used in the production of cosmetics. To maintain and normalize the skin functions, shampoos and creams are enriched with amino acids.

Amino acids in agriculture are traditionally used to enrich fodders, additives and vitamin mixtures. To protect plants from various kinds of diseases, they successfully apply methionine.

Thus, the extensive use of amino acids determines the requirements for their quality in the fermentive and chemical synthesis. Preparation of amino acids of high purity is based on the use of various separation methods.

Separation and analysis of amino acids and their derivatives are used in the determination of amino acid composition of proteins, sequencing of peptides, as well as for the diagnostics of disorders of amino acid and protein metabolism. This section discusses the two most important practically methods of amino acid analysis (Koolman and Rohm, 2000).

A known fact is the separation of optically active amino acids and isomers of their derivatives on the macrocyclic antibiotic "Tikoplanin" (Ananiev et al., 2001). We studied the chromatographic behavior of amino acids and isomers of their derivatives on silica gel modified with the macrocyclic antibiotic "Tikoplanin." It is found that the retention and selectivity of separation of amino acids' derivatives affects mainly the hydrophobicity of the modifier. The possibility of the separation of racemic mixtures of a large number of amino acids without their pre-derivatization is shown.

In the process of separation and detection of amino acids, based on the use of two-dimensional thin layer chromatography on silica gel, the result is achieved by using two solvent systems sequentially: Isopropyl alcoholacetone-ammonia-water and chloroform-ethanol-acetic acid-water. The separated amino acids are stained with the ninhydrin reagent; herewith, the Ehrlich and Nessler's reagents are additionally used (Gorshkov et al., 2010).

For the separation of mixtures of amino acids (proline-valine, tyrosine-phenylalanine) obtained by the microbiological method, the highly basic anionites that have better absorbency than cationites are widely used (Chikina and Miagkova, 1984). Porous anionites, such as AV-17, are the most widely used. The division comprises the following successively executed steps:

- Sorption of the mixture of amino acids on anionite

- Washing anionite after the sorption with water

- Desorption of neutral amino acids with $0.5 \mathrm{~mol} / \mathrm{dm}^{3}$ $\mathrm{HCl}$ solution

- Washing anionite after desorption with water

- Transfer of the $\mathrm{Cl}$-of anionite into the $\mathrm{OH}$-form
At $\mathrm{pH}$ 6.0-6.5, proline is in the initial solution in the bipolar ion form and valine-in the anion form. Thus, the separation of these amino acids on the anion exchanger in the $\mathrm{OH}$ form is achieved. It was found that proline is desorbed in a small amount, whereas the concentration of valine in the eluates exceeds the initial by 4-6 times. Therefore, valine separation is provided by applying regenerative solutions obtained after the separation of proline (Ivanov, 1999).

Biochemistry widely uses high-voltage electrophoresis on inert supports. Separation of amino acids takes place under the influence of the applied electric current, inert supports-polyacrylamide gel or thin layers of cellulose powder. Separation is carried out for $0.5-2 \mathrm{~h}$ at a voltage of 2,000-5,000 V, depending on the total charge of ampholytes and their molecular weight. In an electric field, ions having a negative charge at the given $\mathrm{pH}$ migrate to the anode and the positive to the cathode. The dried electrophoretogram is developed with the ninhydrin solution. The $\mathrm{pH}$ value is determined by the value of $\mathrm{pK}$ of the dissociating groups of molecules of amino acids making up the mixture. At $\mathrm{pH}$ 6.4, glutamate and aspartate are concentrated on the anode and separated by differences in molecular masses. Lysine, arginine and histidine are moved in the opposite direction; glycine, leucine and proline are localized at the site of a tested sample application (Murray, 1993).

We developed the extraction methods for separating mixtures of aromatic amino acids, followed by the spectrophotometric analysis of concentrates; as well as the separate determination of $\alpha$-amino acids by the methods of potentiometric and conductometric titration of extracts based on hydrophilic solvents (Mokshina, 2007). Based on the established patterns of extraction, the algorithm for separating mixtures of $\alpha$-amino acids, as well as $\alpha$-amino acids and vitamins in some pharmaceuticals and food products, was developed. The conditions for efficient separation (concentration of the salting-out agent and certain components of the mixture) were optimized. We calculated the factors of separating mixtures of $\alpha$-amino acids, the ascorbic or nicotinic acid and $\alpha$-amino acids. The maximum factors of phenylalanine and tyrosine separation are achieved in systems with $\mathrm{NaF}$ or $\mathrm{NaCl}$ (710 and 450 respectively). In these conditions, the degree of extraction of phenylalanine reaches $95 \%$ and tyrosine- $4 \%$. We developed systems (on the butyl alcohol base) for effective separation of ascorbic acid and $\alpha$-amino acids.

We studied the extraction separation of tyrosine and glycine and developed the method for extractive separation of tyrosine and glycine with the use of a ternary mixture of hydrophilic solvents. For the analysis of the non-aqueous concentrate, we applied for the first time the method of capillary electrophoresis. The results indicate the possibility of complete separation of 
tyrosine and glycine at single extraction (Pakhomov and Korenman, 2007).

The technique for determining the essential amino acids in complex biological matrices (hydrochloric acid extracts of prostate and pancreatic glands, animal fodder and meat samples) by the method of reverse phase HPLC with UV detection using acid hydrolysis and amino acid modification with phenyl isothiocyanate solution in isopropyl alcohol to give phenylthiohydantoin. The influence of $\mathrm{pH}$ of the mobile phase on the amino acids' separation factors was determined. The conditions for acid hydrolysis of samples during the sample preparation procedure were optimized (Rudenko et al., 2010).

The purpose of this study was to improve the efficiency of separation of amino acids of various structure using soluble polymers as extractants.

The research objects were amino acids of different structures: Heterocyclic histidine, sulfur-containing methionine and the imino acid proline (Fig. 1).

Methionine (2-amino-4-(methylthio) butanoic acid) is characterized by the presence of the easily movable methyl group used for the synthesis of important compounds in the body (choline, creatine, thymine, epinephrine, etc.). Methionine has radioprotective properties. It protects the body when poisoned with bacterial endotoxins and other toxins, so it is often used to protect the body from environmental toxins.

On the basis of amino acids, various drugs have been created to cure memory loss, cerebral vascular atherosclerosis, as well as cerebral circulatory disorders after a stroke were developed. Moreover, amino acids in medicine, particularly in cardiology, are used to treat the coronary heart disease, as well as various arrhythmias (Belikov, 1996).

Sufficiently effective is the use of amino acids as nutritional supplements. Such supplements are used as therapeutic components, as well as elements regulating the nutritional value of foodstuffs (Komov and Shvedova, 2004).

Histidine (L- $\alpha$-amino- $\beta$-imidazolyl-propynoic acid) is an $\alpha$-amino acid of the heterocyclic type. It is one of the essential proteinogenic amino acids. It is an important component of many proteins in the human body. Histidine is needed for protein synthesis, as it is a precursor of histamine, which influences the blood pressure and gastric acid secretion. In addition, histidine participates in the functioning of most enzymatic centers, activating the process of enzymes production. This amino acid is an important participant in the processes of growth and repair of cells and tissues of the body. It is widely used as a dietary supplement in sport and traditional medicine: Histidine is included in the complex therapy treatment of arthritis, ulcers, allergies and anemia.<smiles>CSCCC(N)C(=O)O</smiles><smiles>O=C(O)C1CCCN1</smiles>

Fig. 1. Structures of amino acids

Proline (pyrrolidine- $\alpha$-carboxylic acid). An important example of the modification of amino acid residues is the conversion of proline residues in the hydroxyproline residues, which takes place at the formation of the essential protein component of the connective tissue-collagen.

\section{Materials and Methods}

As extractants, in the work for the first time the water-soluble polymers with different structures were used: Poly-N-vinylpyrrolidone (PVP), Poly-Nvinylcaprolactam (PVC), Polyvinylformamide (PVF), Poly-N-vinylimidazole (PVI), Poly-1-Vinyl-1,2,4Triazole (PVT), Polyacrylamide (PAA), as well as copolymers of N-vinylcaprolactam with Nvinylimidazole (VC-VI) and $\mathrm{N}$-vinylcaprolactam with N-vinylformamide (VC-VF) (Fig. 2).

These polymers are ecologically safe, economically efficient, they demonstrate high complexing ability in relation to amino acids. Previously, these polymers have been successfully used by us for the extraction of aromatic amino acids from aqueous media and therefore their use for the extraction of histidine, proline and methionine is also very promising (Tsyplukhina, 2006; Shatalov et al., 2006; Gendrikson et al., 2006).

For the purpose of the work, the polymers with average molecular weight $(\mathrm{M \eta})$ from 10,000 to 94,000 were synthesized. Radical polymerization was carried out in isopropanol with the change of the monomer concentration within the range of $0.07-2.82 \mathrm{~mol} / \mathrm{dm}^{3}$ during $8 \mathrm{~h}$ at $65^{\circ} \mathrm{C}$. The concentration of the initiatorAzobisisobutyronitrile-was $1 \times 10^{-2} \mathrm{~mol} / \mathrm{dm}^{3}$. The magnitude of the mid-viscosity molecular weight of homopolymers $\mathrm{M}_{\eta}$ was calculated by the Mark-KuhnHouwink's equation from the experimentally found values of the intrinsic viscosity $[\eta]$.

Copolymers were characterized by the $[\eta]$ value determined at $20^{\circ} \mathrm{C}$ in ethyl alcohol. The intrinsic viscosity values were changed within the range $0.1-0.7 \mathrm{~g}$ $\mathrm{dL}^{-1}$ and were close to the corresponding values of the homopolymers. 


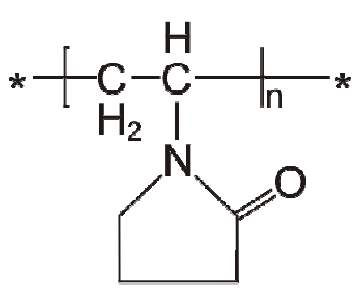

(a)

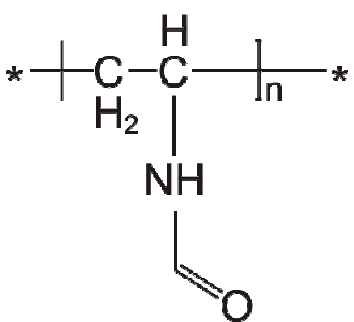

(d)

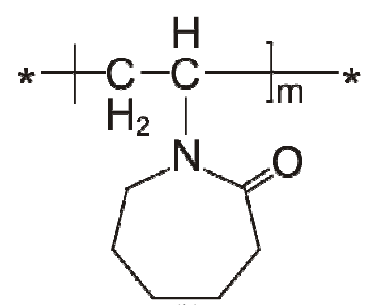

(b)

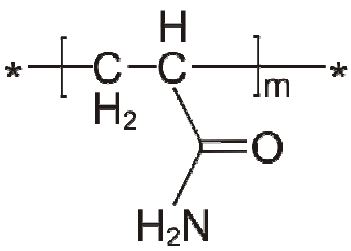

(e)

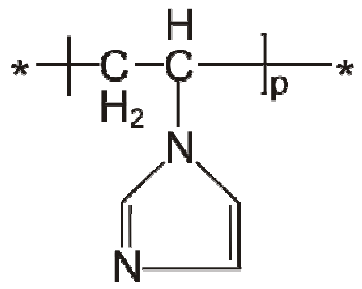

(c)

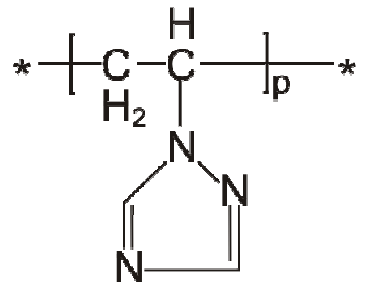

(f)

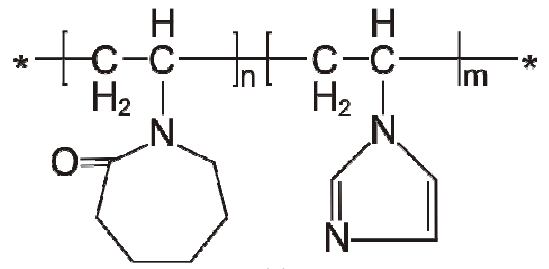

(g)

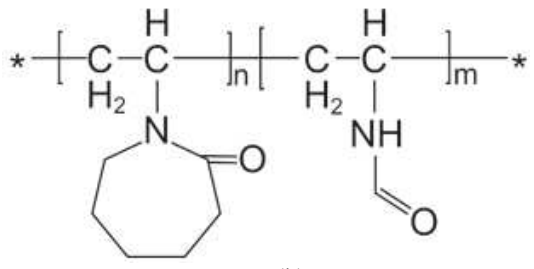

(h)

Fig. 2. The structural formulas of PVP (a) PVC (b), PVI (c), PVF (d), PAA (e), PVT (f) PVC-VI (g), PVK-VF (h)

A

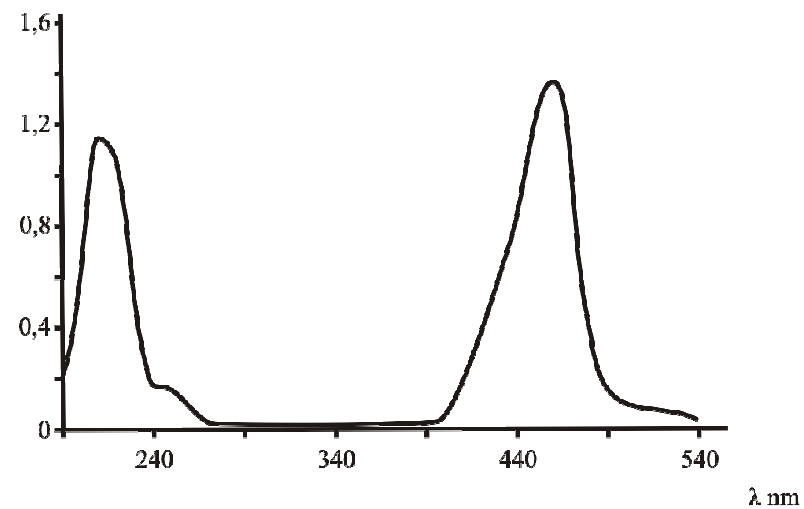

(a)

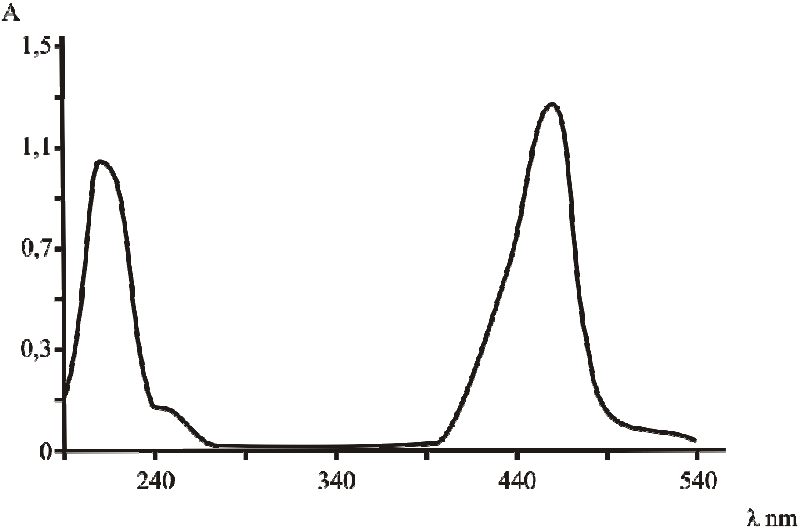

(b)

Fig. 3. UV spectra of absorbance of aqueous salt solutions methionine-proline (a) and histidine-proline (b)

In the graduated tubes with the capacity of $25 \mathrm{~cm}^{3}$, we placed $10 \mathrm{~cm}^{3}$ of the solution of amino acids and 1,2 , or $4 \mathrm{~cm}^{3}$ of aqueous polymer solution with a concentration of $0.12 \mathrm{~g} / \mathrm{cm}^{3}$.

In order to separate the independent organic phase during the extraction of amino acids, we used the salting-out agent-the saturated ammonium sulfate solution. The extraction was fulfilled with a vibromixer during $10 \mathrm{~min}$ at a temperature of $20 \pm 1^{\circ} \mathrm{C}$. In order to set the complete interfacial equilibrium and complete delamination of the system, the extraction system was centrifuged at 10,000 rpm for $15 \mathrm{~min}$. We measured the ratio of the equilibrium aqueous water $\left(\mathrm{V}_{\mathrm{w}}\right)$ and organic $\left(\mathrm{V}_{\mathrm{o}}\right)$ volumes of phases $\left(r=\mathrm{V}_{\mathrm{w}} / \mathrm{V}_{\mathrm{o}}\right)$. The aqueous salt phase was separated from the organic phase and analyzed by UV spectrophotometry method (spectrophotometer Shimadzu UV1800). Preliminarily, we determined the spectral absorption maximums of amino acids in aqueous salt solutions: $\lambda_{\text {His }}=211 \mathrm{~nm}$, $\lambda_{\text {Met }}=209 \mathrm{~nm}$ and $\lambda_{\text {Pro }}=450$. 


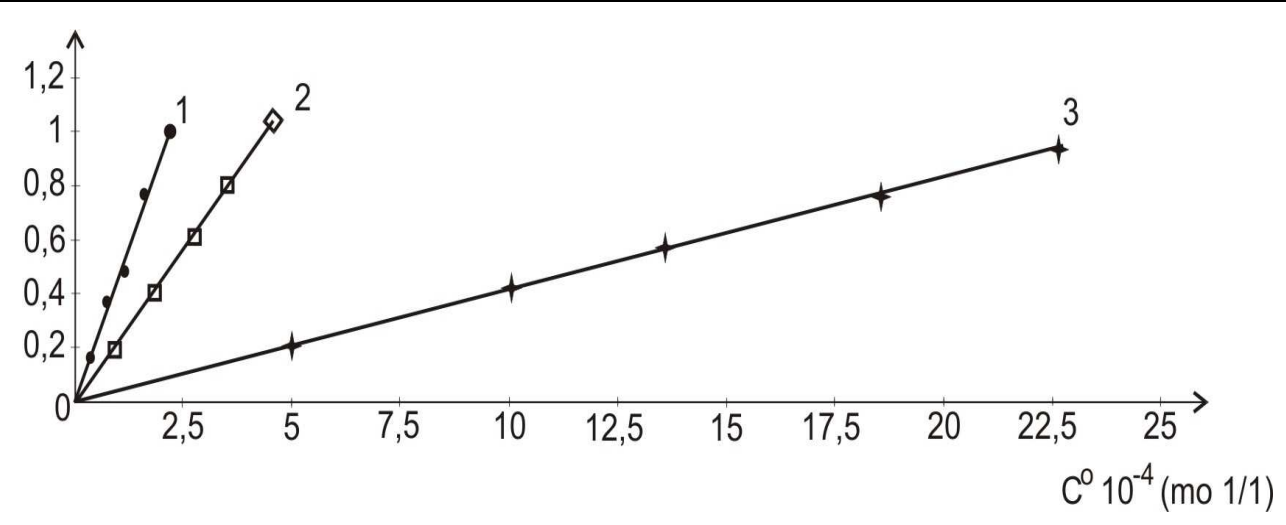

Fig. 4. The calibration curve for the determination of histidine (1), proline (2), methionine (3) in aqueous solution at characteristic wavelengths

The absorption spectrums of analytes do not overlap enabling to carry out separate detection of amino acids by the calibration curve (Fig. 3 and 4 ).

We calculated the extraction characteristics of amino acids extraction: The distribution coefficients (D), the extraction rate $(\mathrm{R}, \%)$ and the separation factors $(\beta)$ by the following formulas:

$$
D=\frac{c_{o}}{c_{6}}, R=\frac{D}{D+r} \cdot 100 ; \beta=\frac{D_{2}}{D_{1}}
$$

\section{Results}

During the research, we studied the extraction separation of mixtures of the amino acids Met-Pro and His-Pro in the systems with water-soluble polymers at different ratios of the equilibrium aqueous and organic phases (Table 1 and 2) and the polymer composition.

By analyzing the above data table, we can conclude that for the amino acids separation, the most effective ratio of the aqueous phase of amino acids and the organic phase of the polymer solution is $r=10: 2$. With other ratios of the phases both amino acids are extracted equally, that does not allow their separation for subsequent quantification.

Based on the experimental data, we calculated the extraction degrees and the separation factors in the methionine-proline and histidine-proline systems. It should be noted that by increasing the polymer concentration above $0.12 \mathrm{~g} / \mathrm{cm}^{3}$, there is no significant increase in the extraction characteristics of amino acids. This is due to the fact that in an aqueous solution of polymers, associates are formed; herewith, the bound water is released and enters into the equilibrium aqueous salt phase (Mokshina, 2007).

It was found that with increasing the average molecular weight of the homopolymers, the efficiency of amino acids separation increases, which is evidenced by the separation factor $\beta$ (Table 1). Herewith, the rate of separation of the systems "water-soluble polymeraqueous salt solution" also depends on the molecular weight of the extractant: As M increases, ${ }_{\eta}$ the amount of polymer required for the formation of a heterogeneous system reduces (Kirsh, 1998; Sukhanov et al., 2013).

The highest factors of the separation of methionine and proline, as well as histidine and proline, are observed for the systems based on PVP with $\mathrm{M}_{\eta}=$ $94 \cdot 10^{3}$ : 109.2 and 92.4 , respectively. Unlike aliphatic methionine, histidine and proline contain heterocycling rings; therefore, the separation in the His-Pro system is less efficient. Obviously, due to the high complexing ability of PVT, PVI and PVF related to the features of their structure and the availability of active sites, their use as extractants for the separation of amino acids is less efficient than PVP and PVC.

In order to increase the separation efficiency, we additionally introduced sodium chloride in the extraction system. For this purpose, the aqueous salt solution of the salting-out agent was supplemented with a sample of sodium chloride, thus achieving the concentration of chloride ions equal to $9 \times 10^{-4} \mathrm{~mol} / \mathrm{dm}^{3}$.

With the increasing concentration of salt, the competing effect of its ions also increases. With account of the small radii of sodium ions and chloride, the salting-out effect of $\mathrm{NaCl}$ increases and the water solubility of polymers decreases (Korenman et al., 2013; Korenman and Niftaliev, 1993). Using the resulting solution as a salting-out agent, we can achieve significant differences in the degree of extraction of amino acids (Table 3 and 4).

Chloride ions react with the protonated amino groups and make them inaccessible to the complexing. The factors of separation of methionine and proline increase significantly compared with the data of Table 1 . We should note the increased efficiency of PVT and PVI as extractants for the separation of these amino acids.

Introduction of chloride ions confirms the nature of the interaction depicted in charts: 
<smiles>CC(C)CN1CCCC1=O</smiles><smiles></smiles><smiles></smiles><smiles>CC(N1CCCC1=O)C(C)(C)C</smiles>

This mechanism of interaction between the polymer and amino acid molecules was confirmed by the results of IR spectroscopic analysis (Shatalov et al., 2014). Presumably, the introduction of chlorine ions forms the salt of the amino acid and blocks the charged amino group, with which further complexing is impossible.

For methionine, it is fully consistent with the experimental data, but for proline and histidine, only a partial reduction in the degree of extraction and complexing probability is observed. This is due to the features of the structure of the amino acids and polymers: The direct complexing is accompanied by reaction of the polymers and amino acids between cycles. There is no cyclic structure in the molecule of methionine, so the probability of complexing is very low. Similar patterns are observed in interaction of PAA and PVF in the systems with histidine and proline.

\section{Discussion}

Table 1-4 show the data on the extraction separation of amino acids with copolymers VC-VI, VC-VF. By varying the composition of the copolymers, one can significantly modify the extraction characteristics of the amino acids. Addition of one of the monomers in the system modifies the conformation of the macromolecule, which is reflected in its ability to self-associate.

However, the use of copolymers did not enable increasing the amino acid separation factors compared to the homopolymer extraction. In the most effective systems (VC-VF in the ratio of 0.87:0.13), the separation factor of methionine and proline is 55.0. Separation of histidine and proline in a similar system is almost two times less. Addition to the extraction system of chloride ions allowed greatly improving the methionine and proline separation factors due to a sharp decrease in the extent of methionine extraction, as its complexing amino group was blocked. 
Nadezhda Yakovlevna Mokshina et al. / American Journal of Applied Sciences 2015, 12 (12): 1032.1041 DOI: 10.3844/ajassp.2015.1032.1041

Table 1. Features of the extraction separation of Met-Pro and His-Pro with water soluble polymers and copolymers in the proportions of the aqueous and organic phases 10:2 $(\mathrm{n}=3, \mathrm{P}=0.95)$

\begin{tabular}{|c|c|c|c|c|c|c|c|c|c|c|}
\hline \multirow{2}{*}{$\begin{array}{l}\mathrm{M}_{\eta} \\
\text { (polymer } \\
\text { composition) }\end{array}$} & \multicolumn{5}{|c|}{ Met (1)-Pro (2) } & \multicolumn{5}{|c|}{ His (1)-Pro (2) } \\
\hline & $\mathrm{R}_{1}, \%$ & $\mathrm{D}_{1}$ & $\mathrm{R}_{1}, \%$ & $\mathrm{D}_{1}$ & $\mathrm{R}_{1}, \%$ & $\mathrm{D}_{1}$ & $\mathrm{R}_{1}, \%$ & $\mathrm{D}_{1}$ & $\mathrm{R}_{1}, \%$ & $\mathrm{D}_{1}$ \\
\hline $\mathrm{PVP}$ & & & & & & & & & & \\
\hline 26 & 5.7 & 0.6 & 81.1 & 38.4 & 65.2 & 5.5 & 0.6 & 78.7 & 36.5 & 59.7 \\
\hline 52 & 4.6 & 0.5 & 77.9 & 35.2 & 71.3 & 4.7 & 0.5 & 76.5 & 34.7 & 63.8 \\
\hline 94 & 3.0 & 0.3 & 73.4 & 26.5 & 84.1 & 3.8 & 0.2 & 65.9 & & 71.3 \\
\hline 12 & 12.7 & 1.4 & 86.2 & 55.3 & 40.1 & 15.1 & 1.8 & 83.8 & 48.9 & 26.7 \\
\hline 32 & 6.1 & 0.6 & 78.4 & 35.6 & 57.2 & 8.7 & 0.9 & 76.7 & 32.1 & 35.4 \\
\hline 50 & 4.5 & 0.5 & 75.8 & 29.2 & 63.5 & 5.9 & 0.6 & 71.0 & 24.2 & 38.2 \\
\hline PVI & & & & & & & & & & \\
\hline 29 & 27.1 & 3.9 & 90.4 & 91.6 & 23.4 & 37.3 & 5.2 & 90.3 & 90.7 & 17.4 \\
\hline 41 & 24.6 & 3.5 & 90.2 & 90.1 & 25.6 & 33.5 & 4.4 & 89.5 & 87.3 & 19.7 \\
\hline $\begin{array}{l}76 \\
\mathrm{PAA}\end{array}$ & 18.5 & 2.7 & 89.5 & 87.2 & 31.7 & 26.6 & 3.8 & 88.6 & 81.7 & 21.1 \\
\hline 34 & 17.5 & 2.1 & 72.0 & 25.2 & 12.1 & 18.1 & 2.6 & 69.1 & 21.4 & 8.0 \\
\hline 56 & 14.7 & 1.8 & 70.8 & 23.6 & 12.7 & 17.9 & 2.2 & 66.0 & 19.5 & 8.8 \\
\hline 82 & 12.2 & 1.6 & 68.3 & 21.1 & 12.9 & 15.2 & 1.9 & 64.3 & 17.8 & 9.0 \\
\hline 38 & 30.4 & 4.2 & 89.8 & 864 & 204 & 412 & 64 & 886 & 813 & 126 \\
\hline 59 & 26.1 & 3.7 & 89.5 & 83.1 & 22.6 & 387 & 58 & 88.0 & 779 & 13.0 \\
\hline 108 & 22.7 & 3.3 & 88.6 & 79.9 & 24.1 & 36.6 & 5.1 & 87.6 & 75.3 & 14.7 \\
\hline PVT & & & & & & & & & & \\
\hline 49 & 23.9 & 3.4 & 88.5 & 78.3 & 22.9 & 35.9 & 50.0 & 87.9 & 76.3 & 15.2 \\
\hline 70 & 18.1 & 2.6 & 87.6 & 75.6 & 29.4 & 31.4 & 4.3 & 87.0 & 72.8 & 16.6 \\
\hline 120 & 15.8 & 20 & 86.8 & 71.2 & 35.1 & 26.5 & 3.7 & 86.5 & 69.3 & 18.4 \\
\hline $0.18: 0.82$ & 35.7 & 5.2 & 92.7 & 116.5 & 224 & 45.1 & 8.5 & 91.0 & 104.1 & 12.2 \\
\hline $0.32: 0.68$ & 29.8 & 4.1 & 91.1 & 104.7 & 25.5 & 42.9 & 7.7 & 89.8 & 95.3 & 12.4 \\
\hline $0.46: 0.54$ & 20.5 & 3.0 & 89.8 & 89.6 & 29.9 & 31.8 & 4.6 & 88.4 & 79.4 & 17.3 \\
\hline $0.54: 0.46$ & 20.1 & 2.5 & 88.4 & 78.2 & 31.3 & 23.9 & 3.2 & 87.5 & 70.2 & 21.9 \\
\hline 0.74:0.26 & 14.1 & 1.6 & 85.7 & 62.3 & 38.9 & 16.6 & 20.0 & 84.7 & 54.5 & 27.3 \\
\hline $0.22: 0.78$ & 361 & 5.5 & 900 & 962 & 17.5 & 487 & 97 & 906 & 1022 & 105 \\
\hline $0.43: 0.57$ & 31.2 & 4.3 & 89.5 & 87.7 & 20.4 & 41.6 & 7.1 & 90.0 & 90.5 & 127 \\
\hline $0.55: 0.45$ & 25.4 & 3.5 & 87.9 & 71.3 & 20.4 & 35.7 & 5.2 & 89.8 & 85.7 & 16.5 \\
\hline $0.76: 0.24$ & 21.0 & 2.7 & 85.1 & 58.4 & 21.6 & 28.4 & 3.9 & 89.5 & 84.6 & 21.7 \\
\hline $0.87: 0.13$ & 9.8 & 1.1 & 82.0 & 49.0 & 44.5 & 16.6 & 20.0 & 82.3 & 50.1 & 25.0 \\
\hline
\end{tabular}

Table 2. Features of the extraction separation of Met-Pro and His-Pro with water soluble polymers and copolymers in the proportions of the

\begin{tabular}{|c|c|c|c|c|c|c|c|c|c|c|}
\hline \multirow{2}{*}{$\begin{array}{l}\mathrm{M}_{\eta} \\
\text { (polymer } \\
\text { composition) }\end{array}$} & \multicolumn{5}{|c|}{ Met (1)-Pro (2) } & \multicolumn{5}{|c|}{ His (1)-Pro (2) } \\
\hline & $\mathrm{R}_{1}, \%$ & $\mathrm{D}_{1}$ & $\mathrm{R}_{2}, \%$ & $\mathrm{D}_{2}$ & $\beta$ & $\mathrm{R}_{1}, \%$ & $\mathrm{D}_{1}$ & $\mathrm{R}_{2}, \%$ & $\mathrm{D}_{2}$ & $\beta$ \\
\hline PVP & & & & & & & & & & \\
\hline 26 & 11.9 & 1.1 & 82.2 & 41.6 & 37.5 & 11.9 & 1.1 & 81.4 & 38.7 & 34.6 \\
\hline 52 & 10.8 & 0.9 & 80.8 & 37.9 & 41.6 & 10.8 & 0.9 & 80.2 & 36.1 & 39.7 \\
\hline 94 & 9.1 & 0.6 & 76.1 & 30.8 & 51.2 & 4.6 & 0.5 & 71.1 & 24.3 & 47.2 \\
\hline \multicolumn{11}{|l|}{ PVC } \\
\hline 12 & 24.2 & 3.1 & 87.1 & 58.2 & 18.3 & 22.7 & 3.3 & 84.3 & 51.2 & 15.1 \\
\hline 32 & 14.3 & 1.6 & 82.3 & 41.1 & 24.8 & 15.8 & 20.0 & 82.0 & 40.7 & 19.8 \\
\hline $\begin{array}{l}50 \\
\text { PYI }\end{array}$ & 11.2 & 10.0 & 77.6 & 33.8 & 32.5 & 12.7 & 1.4 & 77.9 & 34.1 & 23.4 \\
\hline 29 & 46.4 & 8.3 & 90.5 & 93.2 & 11.2 & 483 & 142 & 904 & 912 & 64 \\
\hline 41 & 43.5 & 7.1 & 90.4 & 91.1 & 12.8 & 45.7 & 12.5 & 90.1 & 88.9 & 7.1 \\
\hline 76 & 37.1 & 5.1 & 90.1 & 88.9 & 17.2 & 43.7 & 7.3 & 89.2 & 83.3 & 11.4 \\
\hline 34 & 23.7 & 3.1 & 75.3 & 31.2 & 10.1 & 30.0 & 4.1 & 74.8 & 30.4 & 7.4 \\
\hline 56 & 18.1 & 2.5 & 73.1 & 27.6 & 10.8 & 25.9 & 3.6 & 72.9 & 27.1 & 7.5 \\
\hline 82 & 17.3 & 2.3 & 72.7 & 26.3 & 11.3 & 21.8 & 3.2 & 72.7 & 26.3 & 8.2 \\
\hline 38 & \multicolumn{10}{|c|}{ PVF } \\
\hline 59 & 37.9 & 5.3 & 90.4 & 88.1 & 16.4 & $\begin{array}{l}44.2 \\
43.9\end{array}$ & $\begin{array}{l}0.0 \\
7.9\end{array}$ & 89.8 & $\begin{array}{l}00.1 \\
87.3\end{array}$ & 110 \\
\hline 108 & 35.8 & 50.0 & 89.3 & 83.9 & 16.7 & 43.0 & 7.3 & 89.5 & 85.2 & 11.5 \\
\hline \multicolumn{11}{|l|}{ PVT } \\
\hline 49 & 31.4 & 4.3 & 89.7 & 86.3 & 19.9 & 42.5 & 7.0 & 89.0 & 82.7 & 11.7 \\
\hline 70 & 27.5 & 3.8 & 89.2 & 83.2 & 21.5 & 39.8 & 6.3 & 88.4 & 79.2 & 12.4 \\
\hline \multicolumn{10}{|l|}{ VC-VI } & 13.3 \\
\hline $0.18: 0.82$ & 60.7 & 12.1 & 93.2 & 121.4 & 100 & 65.2 & 15.2 & 91.7 & 107.7 & 7.1 \\
\hline $0.32: 0.68$ & 51.6 & 9.4 & 92.0 & 109.2 & 10.9 & 63.8 & 14.6 & 90.9 & 102.1 & 7.0 \\
\hline $0.46: 0.54$ & 46.1 & 8.6 & 89.7 & 94.5 & 11.6 & 57.3 & 10.1 & 89.1 & 87.1 & 8.6 \\
\hline $0.54: 0.46$ & 38.8 & 7.0 & 89.1 & 85.1 & 12.2 & 52.0 & 9.6 & 88.8 & 84.2 & 8.8 \\
\hline $0.74: 0.26$ & 30.1 & 4.2 & 87.8 & 70.4 & 16.7 & 44.5 & 8.4 & 86.9 & 67.4 & 8.0 \\
\hline \multicolumn{11}{|l|}{ VC-VF } \\
\hline $0.43: 0.57$ & 46.7 & 8.8 & 90.2 & 92.4 & 10.5 & 66.8 & 15.7 & 90.7 & 96.1 & 6.1 \\
\hline $0.55: 0.45$ & 42.4 & 7.2 & 89.7 & 84.7 & 11.7 & 61.1 & 12.0 & 89.5 & 84.9 & 7.0 \\
\hline $0.76: 0.24$ & 33.9 & 4.7 & 88.3 & 76.9 & 16.4 & 54.2 & 10.2 & 88.6 & 78.5 & 7.7 \\
\hline $0.87: 0.13$ & 17.1 & 20.0 & 86.8 & 64.5 & 32.3 & 48.7 & 9.1 & 87.4 & 66.2 & 7.3 \\
\hline
\end{tabular}


Nadezhda Yakovlevna Mokshina et al. / American Journal of Applied Sciences 2015, 12 (12): 1032.1041 DOI: 10.3844/ajassp.2015.1032.1041

\begin{tabular}{|c|c|c|c|c|c|c|c|c|c|c|}
\hline \multirow{2}{*}{$\begin{array}{l}\mathrm{M}_{\eta} \\
\text { (polymer } \\
\text { composition) }\end{array}$} & \multicolumn{5}{|c|}{ Met (1)-Pro (2) } & \multicolumn{5}{|c|}{ His (1)-Pro (2) } \\
\hline & $\mathrm{R}_{1}, \%$ & $\mathrm{D}_{1}$ & $\mathrm{R}_{1}, \%$ & $\mathrm{D}_{1}$ & $\mathrm{R}_{1}, \%$ & $\mathrm{D}_{1}$ & $\mathrm{R}_{1}, \%$ & $\mathrm{D}_{1}$ & $\mathrm{R}_{1}, \%$ & $\mathrm{D}_{1}$ \\
\hline $\begin{array}{l}\mathrm{PVP} \\
26\end{array}$ & 2.7 & 0.3 & 76.0 & 31.8 & 107.3 & 3.7 & 0.4 & 75.4 & 30.6 & \\
\hline $\begin{array}{l}20 \\
52\end{array}$ & 2.4 & $\begin{array}{l}0.3 \\
0.2\end{array}$ & $\begin{array}{l}70.0 \\
74.9\end{array}$ & $\begin{array}{l}31.8 \\
29.8\end{array}$ & 134.4 & 3.1 & $\begin{array}{l}0.4 \\
0.4\end{array}$ & $\begin{array}{l}15.4 \\
72.8\end{array}$ & $\begin{array}{l}30.0 \\
26.8\end{array}$ & $\begin{array}{l}69.6 \\
76.3\end{array}$ \\
\hline 94 & 13.0 & 0.1 & 63.0 & 17.0 & 114.8 & 1.4 & 0.2 & 58.6 & 14.2 & 80.5 \\
\hline 12 & 7.0 & 0.4 & 82.3 & 44.2 & 119.4 & 10.9 & 13.0 & 81.2 & 41.1 & 31.1 \\
\hline 32 & 3.4 & 0.2 & 73.5 & 26.4 & 118.9 & 5.2 & 0.6 & 72.6 & 25.2 & 40.9 \\
\hline $\begin{array}{l}50 \\
\mathrm{PVI}\end{array}$ & 2.4 & 0.1 & 69.0 & 21.2 & 143.3 & 3.4 & 0.4 & 66.1 & 18.6 & 52.8 \\
\hline 29 & 15.0 & 1.8 & 88.6 & 79.5 & 44.7 & 24.9 & 3.5 & 88.0 & 75.2 & 21.4 \\
\hline 41 & 13.6 & 1.6 & 88.3 & 77.9 & 47.8 & 22.9 & 3.1 & 87.6 & 71.9 & 23.3 \\
\hline $\begin{array}{l}76 \\
\text { PAA }\end{array}$ & 12.1 & 1.4 & 87.8 & 76.0 & 54.1 & 19.5 & 2.6 & & & 26.7 \\
\hline 34 & 10.1 & 10.0 & 50.2 & 15.5 & 16.1 & 13.6 & 1.8 & 52.2 & 15.7 & 8.5 \\
\hline 56 & 8.9 & 0.7 & 45.1 & 12.7 & 17.1 & 13.3 & 13.0 & 43.5 & 12.6 & 9.5 \\
\hline 82 & 7.7 & 0.5 & 37.9 & 9.9 & 19.2 & 11.0 & 10.0 & 40.1 & 11.3 & 11.6 \\
\hline 38 & 17.3 & 2.1 & 87.2 & 68.1 & 31.7 & 29.4 & 4.1 & 87.5 & 69.2 & 16.7 \\
\hline 59 & 13.4 & 1.7 & 85.2 & 65.6 & 38.6 & 26.8 & 3.8 & 86.5 & 66.4 & 17.5 \\
\hline 108 & 11.4 & 13.0 & 82.5 & 62.7 & 47.0 & 21.9 & 2.8 & 83.4 & 64.6 & 22.9 \\
\hline 49 & 10.9 & 10.0 & 81.7 & 62.7 & 60.5 & 18.3 & 2.1 & 79.7 & 61.2 & 29.0 \\
\hline 70 & 8.3 & 0.7 & 76.0 & 57.5 & 86.3 & 14.5 & 1.7 & 76.9 & 58.4 & 34.9 \\
\hline 120 & 6.6 & 0.4 & 72.2 & 54.9 & 123.7 & 13.3 & 12.0 & 74.0 & 56.5 & 45.9 \\
\hline $\begin{array}{l}\mathrm{V} C-\mathrm{V} 1 \\
0.18: 0.82\end{array}$ & 21.9 & 2.8 & 90.3 & 95.5 & 34.0 & 33.3 & 5.1 & 89.2 & 85.0 & 16.7 \\
\hline $0.32: 0.68$ & 17.6 & 2.1 & 89.6 & 87.6 & 40.8 & 29.6 & 4.2 & 88.3 & 78.0 & 18.5 \\
\hline $0.46: 0.54$ & 12.8 & 15.0 & 87.7 & 72.7 & 49.1 & 21.7 & 2.8 & 86.4 & 64.7 & 23.0 \\
\hline $0.54: 0.46$ & 11.4 & 13.0 & 86.1 & 63.9 & 50.8 & 16.8 & 20.0 & 84.7 & 56.8 & 28.1 \\
\hline $0.74: 0.26$ & 6.9 & 0.7 & 81.7 & 45.5 & 61.5 & 9.4 & 1.1 & 79.8 & 40.5 & 38.3 \\
\hline $\begin{array}{l}\mathrm{V}-\mathrm{VF} \\
0.22: 0.78\end{array}$ & 21.4 & & & 781 & 293 & 365 & 57 & 889 & 806 & 14. \\
\hline $0.43: 0.57$ & 18.5 & 2.3 & 87.8 & 71.7 & 31.3 & 32.7 & 4.8 & 88.5 & $\begin{array}{l}0.0 \\
74.0\end{array}$ & 15.3 \\
\hline $0.55: 0.45$ & 13.0 & 1.7 & 85.6 & 59.6 & 35.0 & 24.2 & 3.2 & 85.9 & 61.3 & 19.4 \\
\hline $0.76: 0.24$ & 9.8 & 1.1 & 84.2 & 52.4 & 47.2 & 18.9 & $2 . \overline{3}$ & 84.2 & 53.9 & 23.6 \\
\hline $0.87: 0.13$ & 5.4 & 0.5 & 78.6 & 37.3 & 72.0 & 10.7 & 1.1 & 79.2 & 38.4 & 33.5 \\
\hline
\end{tabular}

Table 4. Features of extraction separation of Met-Pro and His-Pro with water soluble polymers and copolymers with additional injection of chloride ions in the concentration of $9 \times 10-4 \mathrm{~mol} / 1(\mathrm{r}=10: 4, \mathrm{n}=3, \mathrm{P}=0.95)$

\begin{tabular}{|c|c|c|c|c|c|c|c|c|c|c|}
\hline $\mathrm{M}_{\eta}$ & Met ( & $o(2)$ & & & & His & (2) & & & \\
\hline composition) & $\mathrm{R}_{1}, \%$ & $\mathrm{D}_{1}$ & $\mathrm{R}_{1}, \%$ & $\mathrm{D}_{1}$ & $\mathrm{R}_{1}, \%$ & $\mathrm{D}_{1}$ & $\mathrm{R}_{1}, \%$ & $\mathrm{D}_{1}$ & $\mathrm{R}_{1}, \%$ & $\mathrm{D}_{1}$ \\
\hline$\overline{\mathrm{PVP}}$ & & & & & & & & & & \\
\hline 26 & 0.7 & 0.1 & 71.3 & 24.9 & 327.8 & 2.5 & 0.3 & 70.6 & 24.0 & 81.4 \\
\hline 52 & 0.6 & 0.1 & 70.0 & 23.4 & 410.4 & 2.1 & 0.2 & 67.8 & 21.0 & 89.2 \\
\hline 94 & 0.3 & 0.1 & 57.1 & 13.3 & 350.4 & 10.0 & 0.1 & 52.6 & 11.1 & 94.1 \\
\hline PVC & & & & & & & & & & \\
\hline 12 & 1.9 & 0.1 & 78.5 & 34.6 & 364.6 & 7.6 & 0.9 & 77.2 & 32.2 & 36.4 \\
\hline 32 & 0.9 & 0.1 & 68.5 & 20.7 & 363.2 & 3.6 & 0.4 & 67.5 & 19.7 & 47.8 \\
\hline 50 & 0.6 & 0.0 & 63.6 & 16.6 & 437.6 & 2.3 & 0.2 & 60.5 & 14.6 & 61.7 \\
\hline PVI & & & & & & & & & & \\
\hline $\begin{array}{l}29 \\
41\end{array}$ & $\begin{array}{l}4.3 \\
3.9\end{array}$ & $\begin{array}{l}0.5 \\
0.4\end{array}$ & $\begin{array}{l}85.9 \\
85.6\end{array}$ & 62.3 & $\begin{array}{l}136.6 \\
1461\end{array}$ & $\begin{array}{l}18.2 \\
16.6\end{array}$ & 2.4 & 85.2 & 58.9 & 25.0 \\
\hline 76 & 3.4 & 0.4 & 84.9 & 59.6 & 165.1 & 14.0 & $\begin{array}{l}2.1 \\
1.7\end{array}$ & $\begin{array}{l}04.1 \\
83.9\end{array}$ & 53.4 & 31.2 \\
\hline PAA & & & & & & & & & & \\
\hline 34 & 2.8 & 0.2 & 30.9 & 6.9 & 27.8 & 5.1 & 0.6 & 32.6 & 6.9 & 11.0 \\
\hline 56 & 2.5 & 0.2 & 26.7 & 5.6 & 29.6 & 50.0 & 0.5 & 25.5 & 5.6 & 12.4 \\
\hline 82 & 2.1 & 0.1 & 21.3 & 4.4 & 33.1 & 4.0 & 0.3 & 22.9 & 50.0 & 15.1 \\
\hline 38 & 51 & 0.6 & 752 & 302 & 548 & 124 & 14 & 756 & 307 & 217 \\
\hline 59 & 3.8 & 0.4 & 71.8 & 29.1 & 66.6 & 11.1 & 13.0 & 73.9 & 29.4 & 22.8 \\
\hline 108 & 3.2 & 0.3 & 67.7 & 27.8 & 81.2 & 8.7 & 10.0 & 69.0 & 28.6 & 29.8 \\
\hline PVT & & & & & & & & & & \\
\hline 49 & 3.0 & 0.3 & 77.7 & 49.1 & 184.7 & 13.1 & 1.4 & 75.5 & 48.0 & 33.9 \\
\hline $\begin{array}{l}70 \\
120\end{array}$ & 2.3 & 0.2 & 71.3 & 45.1 & 263.5 & 10.2 & 1.1 & 72.3 & 45.8 & 40.9 \\
\hline VC-VI & 1.8 & 0.1 & $6 \% .1$ & 43.1 & $37 \% .7$ & 9.3 & 0.8 & 69.1 & 44.3 & 53.6 \\
\hline $0.18: 0.82$ & 6.7 & 0.7 & 88.0 & 74.9 & 103.7 & 25.1 & 3.4 & 86.7 & 66.7 & 19.5 \\
\hline $0.32: 0.68$ & 5.2 & 0.6 & 87.1 & 68.7 & 124.6 & 22.0 & 2.8 & 85.6 & 61.1 & 21.6 \\
\hline $0.46: 0.54$ & 3.6 & 0.4 & 84.8 & 57.0 & 150.0 & 15.6 & 1.9 & 83.2 & 50.7 & 26.9 \\
\hline $0.54: 0.46$ & 3.2 & 0.3 & 83.0 & 50.1 & 155.1 & 11.9 & 1.4 & 81.3 & 44.6 & 32.8 \\
\hline $0.74: 0.26$ & 1.9 & 0.2 & 77.7 & 35.7 & 187.8 & 6.5 & 0.7 & 75.6 & 31.7 & 44.8 \\
\hline $0.22: 0.78$ & 6.5 & 0.7 & 86.0 & 61.3 & 89.6 & 27.8 & 3.8 & 86.3 & 63.2 & 16.5 \\
\hline $0.43: 0.57$ & 5.5 & 0.6 & 84.9 & 56.2 & 95.5 & 24.6 & 3.2 & 85.7 & 58.0 & 17.9 \\
\hline $0.55: 0.45$ & 3.7 & 0.4 & 82.3 & 46.7 & 106.9 & 17.6 & 2.1 & 82.7 & 48.1 & 22.6 \\
\hline $0.76: 0.24$ & 2.7 & 0.3 & 80.7 & 41.1 & 144.1 & 13.5 & 15.0 & 80.7 & 42.3 & 27.6 \\
\hline $0.87: 0.13$ & 1.4 & 0.1 & 74.3 & 29.3 & 220.0 & 7.4 & 0.8 & 74.9 & 30.1 & 39.2 \\
\hline
\end{tabular}




\section{Conclusion}

We have studied the extraction separation of methionine, histidine and proline in the systems with water-soluble homo- and copolymers. Under identical conditions, we obtained the quantitative characteristics of the separation of amino acids and developed a general framework for the analysis. The influence of the ratio of volumes of the aqueous and organic phases, the composition of polymers, their concentration in aqueous solution on the degree of extraction and the factor of methionine, histidine and proline separation has been studied.

To improve the separation coefficient of the studied amino acids, we have additionally added chloride ions in the in aqueous solution of amino acids-the extractant solution-in the concentration of $9 \times 10^{-4} \mathrm{~mol} / \mathrm{dm}^{3}$. This has resulted in a significant increase in the factor of methionine and proline separation.

As a result of the directed search for stable two-phase systems of water-soluble polymers, we have developed efficient extraction systems for the separation of methionine, histidine and proline, which can be used in the identification and separation of amino acids in multicomponent mixtures. The results can be applied in various fields of chemical analysis at the synthesis of the free forms of amino acids and the production of some groups of preparations based on them.

\section{Acknowledgement}

The research was carried out within of the basic part of the state task of the Ministry of Education and Science of the Russian Federation for 2015.

\section{Funding Information}

This work was financially supported by the Ministry of Education and Science of the Russian Federation within the framework of the state order $\# 2468$.

\section{Author's Contributions}

Nadezhda Mokshina: Developed the conceptual idea, design of the research work and provided critical research reviewing.

Gennadiy Shatalov and Dmitry Bykovskiy: Carried out the experimental research, data collection of the study sample and writing the manuscript, participated in discussion and conclusion.

Oksana Pakhomova: Participated in the results analysis, contributed to the drafting of the article.

\section{Ethics}

This article is original and contains unpublished materials. The corresponding author confirms that all of the other authors have read and approved the manuscript and there are no ethical issues involved.

\section{References}

Ananiev, I.A., E.N. Shapovalova, O.A. Shpigun and D.V. Armstrong, 2001. Separation of the optically active amino acids and isomers o, their derivatives on the macrocyclic antibiotic "Tikoplanin". Chemistry, 42: 278-280.

Belikov, V.G., 1996. Pharmaceutical chemistry: Special pharmaceutical chemistry. Pyatigorsk State Pharmaceutical Academy, Pyatigorsk.

Berezov, T.T. and B.F. Korovkin, 2004. Biological chemistry. Meditsina, Moscow.

Chikina, G.A. and O.N. Miagkova, 1984. Ion exchange methods of substances purification. Voronezh, VSU.

Gendrikson, O.D., A.V. Zherdev and B.B. Dzantiiev, 2006. Molecularly imprinted polymers and their use in biochemical analysis. Successes Biological, 46: 149-192.

Gorshkov, N.I., I.I. Malakhova, V.D. Krasikov, Z.O.S. Zhurlov and Y.B. Ivanov, 2010. Liquid chromatography of platelet proteins. Sorption Chromatographic Processes, 10: 661-668.

Ivanov, V.A., 1999. The role of temperature in the process of separation and purification of substances on ion exchange resins. Theory Practice Sorption Processes: Collection Articles, 25: 234-237.

Ivashov, M.N., 2013. Biological activity of compounds from plant sources. Fundamental Res., 7: 1482-1484.

Kirsh, Y.E., 1998. Poly-N-vinylpyrrolidone and other poly-N-vinyl amides. Nauka, Moscow.

Komov, V.P. and V.N. Shvedova, 2004. Biochemistry. Drofa, Moscow.

Koolman, J. and K.G. Rohm, 2000. Color Atlas of biochemistry (Trans.). Mir, Moscow.

Korenman, Y.I. and S.I. Niftaliev, 1993. Extraction of chlorophenols with hydrophilic solvents. J. Applied Chem., 66: 1763-1766.

Korenman, Y.I., T.V. Chibisova and O.A. Pakhomova, 2013. Distribution coefficients for novocaine in aliphatic alcohol $\left(\mathrm{C}_{3}-\mathrm{C}_{9}\right)$-solvotropic reagentsalting-out reagent-water systems. Russian J. Phys. Chem., 7: 1218-1221.

Mokshina, N.Y., 2007. Extraction of amino acids and vitamins. Voronezh State Technological Academy. Voronezh.

Murray, R., 1993. Human biochemistry: In 2 volumes. Mir, Moscow.

Pakhomov, O.A. and Y.I. Korenman, 2007. Extraction separation of tyrosine and glycine. Modern High Technol., 5: 16-18.

Rudenko, A.O., L.A. Kartsova and S.I. Snarskii, 2010. Identification of critical amino acids in complex biological objects by the method of reverse phase HPLC to give phenylthiohydantoins of amino acids. Sorption Chromatographic Process., 10: 223-230. 
Shatalov, G.V., D.V. Bykovskii, N.Y. Mokshina, V.A. Kuznetsov and T.N. Poiarkova, 2014. Extraction of methionine in two-phase aqueous salt systems with cyclic poly-N-vinyl amides. Chem. Chemical Eng., 57: 73-77.

Shatalov, G.V., V.N. Verezhnikov, T.V. Plaksitskaia, V.A. Kuznetsov and Poyarkova, 2006. The synthesis of copolymers of N,Ndimethylaminoethylmethacrylate and $\mathrm{N}$-vinyl caprolactam and features of their behavior in the processes of the complexing and flocculation actions. High-Molecular Weight Compounds, 48: 1-6.
Sukhanov, G.T., K.K. Bosov, A.G. Sukhanov and Y.V. Filippova, 2013. Assessing the impact of the structure of the block copolymers of polyepichlorohydrins-polyethylene glycols on the nature of the change in their dynamic viscosity. Chem. High-Energy Compounds, 3: 73-76.

Tsyplukhina, Y.V., 2006. Extraction of $\alpha$-amino acids with aromatic substituents with synergistic watersoluble polymers. VSU, Voronezh.

Vorokhobina, N.V. and A.V. Kuznetsov, 2010. New features of metabolic therapy in patients with diabetes mellitus type 1 and 2. Russian Med. J. Endocrinol., 18: 1-2. 